\title{
Cancerous, but not stromal, thrombospondin-2 contributes prognosis in pulmonary adenocarcinoma
}

\author{
TSUYOSHI CHIJIWA $^{1,7}$, YOSHIYUKI ABE ${ }^{3}$, YOSHIMASA INOUE ${ }^{2}$, HOZUMI MATSUMOTO $^{1}$, \\ KENJI KAWAI ${ }^{4}$, MASAHIRO MATSUYAMA ${ }^{2}$, NORIYUKI MIYAZAKI ${ }^{1}$, HIROSHI INOUE $^{2}$, \\ MASAYA MUKAI $^{6}$, YOSHITO UEYAMA ${ }^{1,5}$ and MASATO NAKAMURA ${ }^{1,4}$
}

\author{
Departments of ${ }^{1}$ Pathology and ${ }^{2}$ Surgery, Tokai University School of Medicine, Shimokasuya, Isehara, Kanagawa 259-1193; \\ ${ }^{3}$ Tokorozawa PET Diagnostic Imaging Clinic, Higashi-Sumiyoshi, Tokorozawa, Saitama 359-1124; ${ }^{4}$ Central Institute \\ for Experimental Animals, Nogawa, Kawasaki, Kanagawa 216-0003; Departments of ${ }^{5}$ Pathology and ${ }^{6}$ Surgery, \\ Tokai University Hachioji Hospital, Ishikawa, Hachioji, Tokyo 192-0032; ${ }^{7}$ Japan Self Defense \\ Force Hospital Yokosuka, Tauraminato, Yokosuka, Kanagawa 237-0071, Japan
}

Received March 3, 2009; Accepted April 20, 2009

DOI: $10.3892 /$ or_00000435

\begin{abstract}
Thrombospondin (TSP)-2 is known to be an endogenous negative regulator of vascularization in human cancer. However, it is unclear whether TSP-2 expression is related to neovascularization and prognosis in non-small cell lung cancer. In this study, we quantitatively examined the expression of TSP-2 mRNA by real-time reverse transcription-polymerase chain reaction (RT-PCR) in 102 pulmonary adenocarcinomas. All 102 carcinoma specimens expressed TSP-2 mRNA. The expression of TSP- 2 mRNA in carcinoma was significantly higher than normal lung tissues $(\mathrm{p}<0.0001$, Kruskal-Wallis test). Sizes of tumors were significantly correlated with TSP-2 gene expression $(\mathrm{p}=0.0179$, Kruskal-Wallis test). The TSP-2 expression levels of the stage II/III pulmonary carcinomas were significantly increased as compared to those of stage I ( $\mathrm{p}=0.0136$, Kruskal-Wallis test). Thirty-five patients with high TSP-2 mRNA expression showed poor prognosis in survival ( $\mathrm{p}=0.0139, \log$-rank test). We examined TSP-2 protein localizations in the pulmonary adenocarcinoma overexpressing TSP-2 mRNA. The TSP-2 localizations were categorized in two patterns: cancerous TSP-2 expression pattern (TSP-2 expression in the cancerous cells) and non-cancerous TSP-2 expression pattern (TSP-2 expression in the stromal lymphoid cells). Pulmonary adenocarcinoma patients with cancerous TSP-2 expression pattern showed good prognosis $(\mathrm{p}=0.0322$; Fisher's probability exact test). Pulmonary adenocarcinoma patients with non-cancerous TSP-2 expression pattern showed poor
\end{abstract}

Correspondence to: Dr Masato Nakamura, Department of Pathology, Tokai University School of Medicine, 143 Shimokasuya, Isehara, Kanagawa 259-1193, Japan

E-mail: mnakamur@is.icc.u-tokai.ac.jp

Key words: thrombospondin-2, pulmonary adenocarcinoma, prognosis prognosis ( $\mathrm{p}=0.0220$; Fisher's probability exact test $)$. Noncancerous TSP-2 expressions may reflect secondary reactions in the cancerous stroma. The stromal TSP-2 expression is not enough to suppress growth of pulmonary adenocarcinoma, while the cancerous TSP-2 expression directly inhibits growth of the carcinoma.

\section{Introduction}

Lung cancer is one of the most common malignant diseases in the world, and its prognosis is generally poor. Among several histological types of lung carcinoma, pulmonary adenocarcinoma makes up approximately half of the nonsmall cell lung cancer (NSCLC) and shows a variety of histopathological features. Surgical resection is currently the only method of possibly curing lung cancer; however, more than $50 \%$ of such patients who undergo a complete resection have a recurrence. Development of cancer growth and metastasis involves numerous biological steps, including angiogenesis in both the primary and the metastatic sites. A tumor with a rich vascularization is likely to grow more rapidly and have a high risk of metastasis.

TSP is a family of glycoproteins with at least five subtypes encoded by independent genes, in which TSP-1 and TSP-2 contain three properdin-like type- 1 repeats, unlike other TSPs (1-6). TSP-2 is a 420-kDa homotrimeric extracellular matrix protein. TSP-2 has recently attracted attention as an endogenous negative regulator of angiogenesis in tumorigenesis $(7,8)$. Since TSP-2 shows poor sequence homology to TSP-1 in the procollagen region but good matches in the type- 1 repeats region, it has been suggested that the antiangiogenic activity of TSP-2 maps to the type-1 repeats (9). However, further functions and properties of TSP-2 are not well understood $(7,10)$, while many studies have revealed those of TSP-1 (11-13). Human TSP-2 mRNA is expressed at high levels in aortic, cardiac, muscle, fetal, endocrine, immune and nervous tissues (10).

Some studies have reported that TSP expressions are related to tumor neovasculization and prognosis in various 
neoplasms. We previously reported that TSP-2 gene expression detected by semi-quantitative reverse transcriptionpolymerase chain reaction (RT-PCR) is significantly correlated with decreased vascularity in various tumor tissues including NSCLC (14-16). We have also reported good prognosis in patients with pulmonary adenocarcinoma expressing TSP-2 mRNA (14). On the other hand, Fontanini et al reported no statistical differeces between TSP-2 mRNA expression and microvessel density in NSCLC by RT-PCR (17). Thus, it is still confusing whether TSP expression is related to neovasculization and prognosis in NSCLC.

In this study, we examined in detail and quantitatively the gene expression of TSP-2 by real-time PCR in 102 cases of pulmonary adenocarcinoma obtained by complete surgical resection. We discuss herein the relationshiop between cancerous or non-cancerous expressions of TSP-2 and clinicopathological features in pulmonary adenocarcinoma.

\section{Materials and methods}

Patients. One hundred and two pulmonary adenocarcinoma specimens were obtained from surgical specimens with the patients' informed consent from October 1985 to November 1995. Tissues were immediately frozen and stored at $-80^{\circ} \mathrm{C}$ until analysis. Surgical specimens were also processed for routine histopathological analysis. The pathological features of the samples were classified according to the WHO histological criteria (18).

The patient consisted of 56 men and 46 women with a mean age of $62.98 \pm 9.52$ years. Tumor status was T1 in 46 patients, T2 in 44, T3 in 8 and T4 in 4. Fifty-seven patients had no lymph node metastasis (N0), whereas 43 patients had lymph node metastasis (N1 in 14, N2 in 28 and N3 in 1) and 2 patients had unknown $\mathrm{N}$ status $(\mathrm{Nx})$. The pathological stages were as follows: stage I, 55 patients; stage II, 13; stage III, 34; and stage IV, 0 .

Quantitative evaluation of TSP-2. Total cellular RNA was prepared from the frozen specimens by standard acid guanidine isothiocyanate-phenol-chloroform extraction procedures. After heat-denaturation of total RNA specimens $(1 \mu \mathrm{g})$, reverse transcription was performed [10 mM DTT (Invitrogen Corp., Carlsbad, CA, USA), 0.2 mM dNTPs (Toyobo Co., Osaka, Japan), 100 pmol of Primer, Random PD (N6) (Roche Diagonostics Co., Indianapolis, MN, USA) and 200 Unit of Superscript ${ }^{\mathrm{TM}}$ II RNase H-Reverse Transcriptase (Invitrogen) at $\left.42^{\circ} \mathrm{C}, 60 \mathrm{~min}\right](19,20)$. Realtime quantitative PCR for TSP-2 was performed according to the manufacturer's recommendation. The primers used for TSP-2 were as follows: 5'-primer: GCTGGTTCAGACAGC CAACTC; 3'-primer: TAACCAAAGACGAAGCCAGCAT; probe: FAM-TGCCACTGAAGTCCACAGACCCAAACTTAMRA. We used TaqMan ${ }^{\circledR}$ Universal PCR Master Mix (PE Applied Biosystems, Foster City, CA, USA) for the real-time PCR. For the internal controls, $B$-actin-probe-primer mixture for $\beta$-actin mRNA was used (human ACTB, 4310881E, PE Applied Biosystems). Real-time PCR assays were duplicated on an ABI PRISM7000 Sequence Detection System (PE Applied Biosystems) with the following protocol: after initial denaturation, $2 \mathrm{~min}$ at $50^{\circ} \mathrm{C}$ and $10 \mathrm{~min}$ at $95^{\circ} \mathrm{C}$; amplification, 50 cycles of $15 \mathrm{sec}$ at $95^{\circ} \mathrm{C}$ and $60 \mathrm{sec}$ at $60^{\circ} \mathrm{C}$. The standard for TSP-2 is A375 (human malignant melanoma cell line). After determining the threshold cycle $(\mathrm{Ct})$, which was defined as the PCR cycle number at which point the fluorescent intensity exceeded the threshold from the $\mathrm{Ct}$ of the sample and the RNA standard curve. Then, the relationship between the $\mathrm{Ct}$ and the initial standard copy number was expressed as a logarithmic formula. The obtained copy of each gene was then standardized with the $B$-actin mRNA quantity as the endogenous control using the following equation: Result = $\log$ (RNA copy number of each gene in sample/ß-actin RNA copy number in sample) $\mathrm{x}\left(6.1 \times 10^{9}\right)$.

Immunohistochemistry. Briefly, sections were incubated in $0.3 \% \mathrm{H}_{2} \mathrm{O}_{2}$ in methanol, washed in phosphate-buffered saline (PBS) and non-specific protein binding was blocked with normal rabbit serum (Nichirei, Tokyo, Japan). Sections were then incubated overnight in a humid chamber at $4^{\circ} \mathrm{C}$, with affinity purified goat antibodies specific to TSP-2 (sc-7655, Santa Cruz Technology, Inc., Santa Cruz, CA, USA) diluted at 1:100 in PBS. Following three PBS washes, sections were incubated with peroxidase-labelled polymer conjugated rabbit anti-goat antibody (Histofine Simplestain Max-PO; Nichirei, Tokyo, Japan). The amplified immune products were visualized using a 3,3'-diaminobenzidine tetrahydrochloride reaction.

Statistical analysis. Statistical comparisons of data sets were performed by non-parametric analysis using Kruskal-Wallis test. Fisher's probability exact test was applied for comparisons between group frequencies, and p-one side probabilities were calculated. Differences in survival between subgroups of patient were compared with the log-rank test, and survival curves were plotted according to the method of Kaplan-Meier. Data are shown as means \pm standard deviation (SD). These analyses were performed using the JMP version 6 software (SAS Institute, Inc., Cary, NC, USA). P-values $<0.05$ were considered statistically significant.

\section{Results}

Expression levels of TSP-2 mRNA in pulmonary adenocarcinoma. All pulmonary adenocarcinoma and normal lung tissues showed significant expression of TSP-2 mRNA by real-time PCR: TSP-2 in pulmonary adenocarcinoma, 1.976 \pm 2.267 ; TSP-2 in normal lung tissues, $0.539 \pm 0.712$ (Table I). The gene expression levels of TSP-2 in pulmonary adenocarcinoma were significantly higher than normal lung tissues $(\mathrm{p}<0.0001$, Kruskal-Wallis test). The correlations were not significant between the gene expression levels of TSP-2 and the age/ gender in pulmonary adenocarcinoma (age, $\mathrm{p}=0.0765$; gender, $\mathrm{p}=0.8035$, Kruskal-Wallis test).

The TSP-2 expression levels in T3 and T4 were significantly higher than in $\mathrm{T} 1$ and $\mathrm{T} 2$ pulmonary adenocarcinoma (sizes of tumors: $\mathrm{T}$ status, $\mathrm{p}=0.0179$, Table I). The TSP-2 gene expression levels showed no significant correlations with nodal involvement (N status). The TSP-2 expression levels in stages II and III were significantly higher than in stage I pulmonary adenocarcinoma $(\mathrm{p}=0.0136)$.

Correlations between prognosis and TSP-2 expression levels in pulmonary adenocarcinoma. TSP-2 expression levels were 
Table I. TSP-2 gene expression in pulmonary adenocarcinoma.

\begin{tabular}{lc}
\hline Type (n) & TSP-2 expression \\
\hline Pulmonary adenocarcinoma (102) & $1.976 \pm 2.267^{\mathrm{a}}$ \\
Lung tissue (20) & $0.539 \pm 0.712^{\mathrm{a}}$ \\
Age & \\
$<60(37)$ & $1.518 \pm 1.395$ \\
$\geq 60(65)$ & $2.237 \pm 2.613$ \\
Gender & \\
Male (56) & $1.974 \pm 2.387$ \\
Female (46) & $1.979 \pm 2.138$ \\
T status & \\
T1+T2 (90) & $1.778 \pm 1.888^{\mathrm{b}}$ \\
T3+T4 (12) & $3.464 \pm 3.951^{\mathrm{b}}$ \\
N status & \\
N0 (57) & $1.797 \pm 2.377$ \\
N1+N2+N3 (43) & $2.248 \pm 2.160$ \\
Stage & \\
I (55) & $1.512 \pm 1.535^{\mathrm{c}}$ \\
II+III (47) & $2.520 \pm 2.821^{\mathrm{c}}$ \\
Distant metastasis found after surgery & \\
Yes (40) & $2.596 \pm 3.127$ \\
No (62) & $1.577 \pm 1.358$ \\
\hline N & \\
\hline
\end{tabular}

Kruskal-Wallis test; ${ }^{\mathrm{a}} \mathrm{p}<0.0001 ;{ }^{\mathrm{b}} \mathrm{p}=0.0179 ;{ }^{\mathrm{c}} \mathrm{p}=0.0136$.

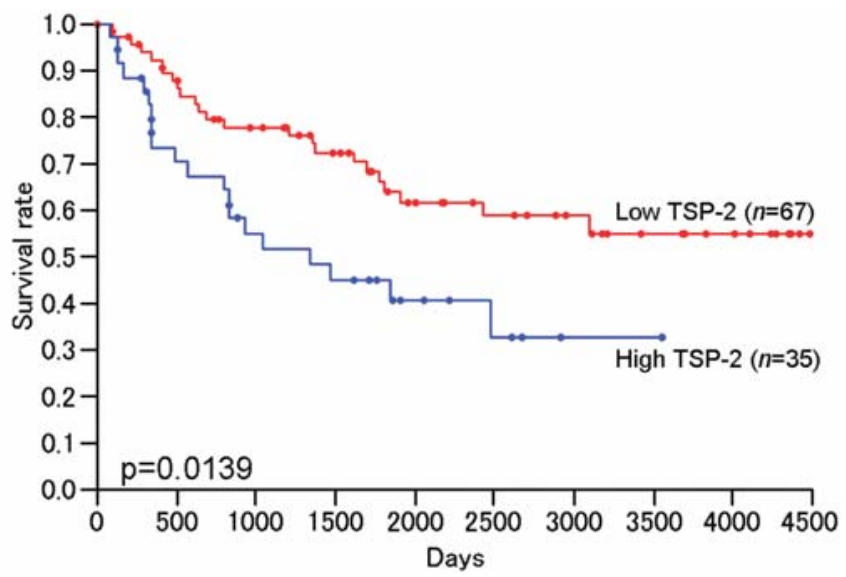

Figure 1. Overall survival of 102 completely resected patients with pulmonary adenocarcinoma, stratified by TSP-2 mRNA expression.

not significantly correlated with distant metastasis found after surgery ( $\mathrm{p}=0.0918$, Table I). The high TSP-2 pulmonary adenocarcinoma patients (35 patients, TSP-2 levels: higher than mean level) significantly showed poorer prognosis than the low TSP-2 patients ( $\mathrm{p}=0.0139$, log-rank test, Fig. 1).

Correlations between prognosis and TSP-2 localization in pulmonary adenocarcinoma. We immunohistochemically

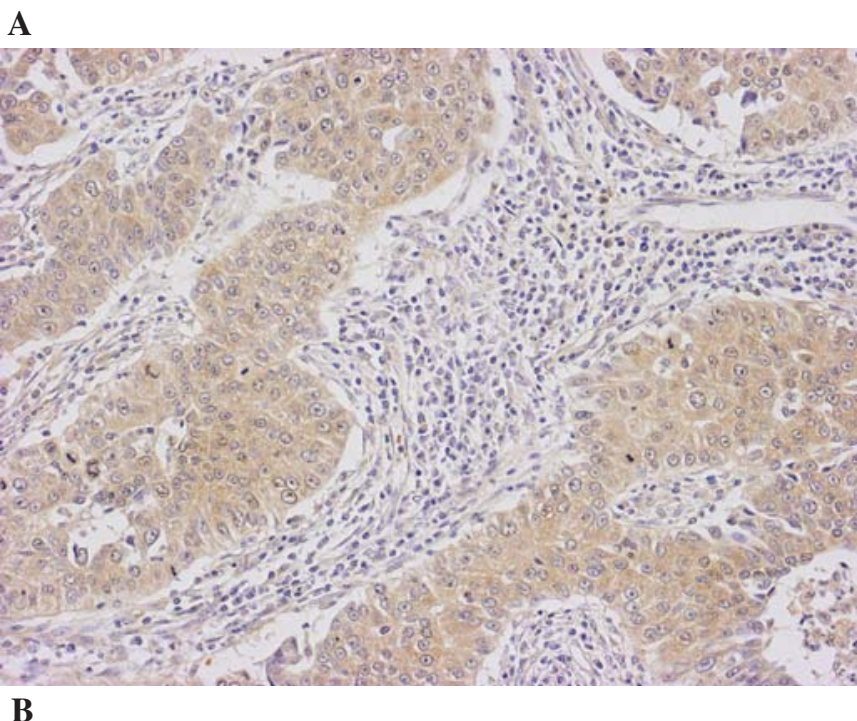

B

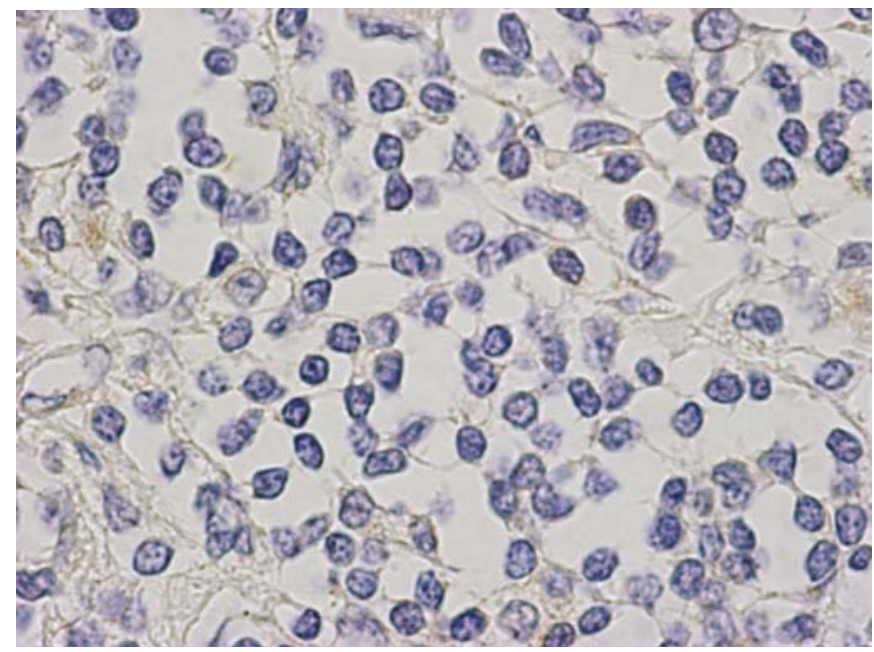

C

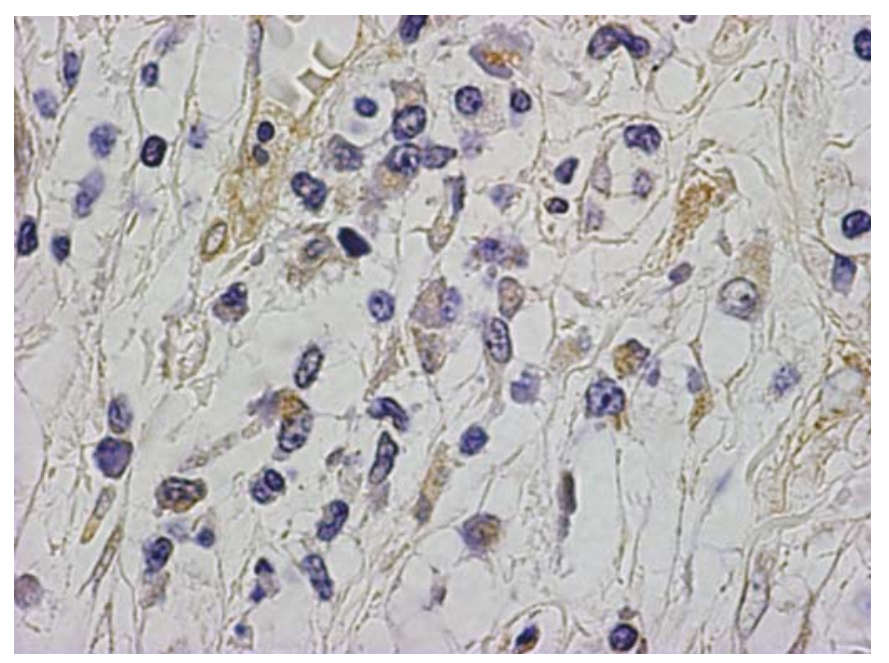

Figure 2. Immunohistochemical expression of TSP-2. Cases with high TSP-2 expression level and good prognosis (alive $>2$ years) showed strong cancerous expression [(A) x25] but not in lymphocytes [(B) x138]. Cases with high TSP-2 expression level but poor prognosis (died within 2 years) showed low expression in tumor cells but high levels in lymphocytes [(C) x138].

confirmed the localization of TSP-2 protein in pulmonary adenocarcinoma. TSP-2 protein localizations were categorized as two patterns: cancerous TSP-2 expression pattern (TSP-2 expression in the cancerous cells, Fig. 2A and B) and non- 
Table II. Immunohistichemical TSP-2 protein expression in high TSP-2 group.

\begin{tabular}{|c|c|c|c|c|c|c|}
\hline \multirow[b]{2}{*}{ Survival days } & \multicolumn{2}{|c|}{ Cancerous overexpression } & \multirow[b]{2}{*}{ P-value } & \multicolumn{2}{|c|}{ Stromal overexpression } & \multirow[b]{2}{*}{ P-value } \\
\hline & $(+)$ & $(-)$ & & $(+)$ & $(-)$ & \\
\hline$<2$ years & 3 & 5 & 0.0322 & 6 & 2 & 0.0220 \\
\hline$\geq 2$ years & 12 & 2 & & 3 & 11 & \\
\hline
\end{tabular}

Fisher's probability exact test.

cancerous (stromal) TSP-2 expression pattern (TSP-2 expression in the lymphoid cells, Fig. 2C). The patients alive more than 2 years (14 patients) predominantly showed cancerous TSP-2 pattern ( $\mathrm{p}=0.0322$, Fisher's probability exact test, Table II), while the patients who died within 2 years ( 8 patients) predominantly showed the stromal TSP-2 pattern $(\mathrm{p}=0.0220)$.

\section{Discussion}

There is increasing evidence that TSP-2 plays a major role in the regulation of primary angiogenesis $(5,6)$. TSP-2 is considered to promote apoptosis and inhibit proliferation of microvessel endothelial cells $(21,22)$. In this study, we showed that gene expression levels of TSP-2 were obviously increased in the tumor. The TSP-2 expression levels were significantly correlated with sizes of tumor and pathological stages. Moreover, enhanced TSP-2 expression levels were correlated with worse prognosis in pulmonary adenocarcinoma. We previously reported that TSP-2 gene expression was significantly correlated with better prognosis in pulmonary adenocarcinoma (14). The results presented here appear to be contradictory to the previous study. In the previous study, gene expressions of TSP-2 were evaluated by conventional and non-quantitative RT-PCR methods. In this study, we used the quantitative real-time RT-PCR procedures. We also analyzed localization of TSP-2 in the tumor. We showed here that cancerous TSP-2 expression patterns were correlated with better prognosis in pulmonary adenocarcinoma, whereas stromal TSP-2 expression patterns were correlated with worse prognosis. The contradictory results obtained by studies with bulk materials did not reflect theses TSP-2 localizations. We were able to explain in detail the TSP-2 expression in prognosis of pulmonary adenocarcinoma in this study.

Streit et al reported that squamous cell carcinoma cell lines transfected with murine TSP-2 showed inhibited dermal microvascular endothelial cell migration in vitro and intradermal tumor growth in vivo (4). In our previous reports, colon cancer cell lines transfected with human TSP-2 showed decresed proliferation of microvascular endothelial cells in vitro and the down-regulated expression of matrix metalloproteinase (MMP)-2 and 9 mRNA $(23,24)$. Pancreatic cancer cell lines transfected with TSP-2 showed fewer invasions in vitro through the down-regulation of MMP-9 and urokinase type plasminogen activatior activities (25). In malignant melanoma xenografts, the overexpression of
TSP-2 inhibited hematogenous metastasis in vivo (26). In these results, tumor cells secreting TSP-2 show fewer invasive properties and result in better prognosis because of the anti-angiogenic effect of TSP-2.

The stromal up-regulation of the endogenous angiogenesis inhibitor TSP-2 is supposed to play a protective role in multistep carcinogenesis as part of host anti-tumor defense mechanisms (27). Stromal TSP-2 expressed in the dermis has been shown to inhibit angiogenesis in response to a foreign body implant (28). The TSP-2 expression was highly upregulated in the mesenchymal tumor stroma throughout the consecutive stages of skin tumorigenesis (27). TSP-2 deficiency dramatically enhanced the susceptibility to experimental skin carcinogenesis. TSP-2 deficiency was also associated with increased tumor angiogenesis and decreased tumor cell apoptosis. Vascularity in the cancer stoma is regulated by the balance between various angiogenic and angio-inhibitory factors. Therefore, the stromal TSP-2 overexpression means a reactive phenomenon due to a highly angiogenic tumor progression, which could lead to a worse prognosis.

It is difficult to distinguish whether TSP-2 is overexpressed in the tumor cells or reactively expressed in the mesenchymal tumor stroma by the quantitative real-time PCR with bulk materials. In this study, TSP-2 mRNA were detected in all the cases whereas in only half of the cases by conventional RT-PCR in our previous study (14). It may explain why the correlations between prognosis and the expressions of TSP-1 and -2 are still controversial $(14,17,29,30)$. We plan to study how the cancerous TSP-2 overexpression effects the tumor invasion and angiogenesis by TSP-2 transfectants of pulmonary adenocarcinoma cell lines.

\section{Acknowledgements}

We are grateful to Johbu Itoh PhD and Mr. Yuichi Tada (Department of Pathology, Tokai University), and Toshiyuki Suganuma MD (Yokosuka General Hospital Uwamachi) for their technical assistance and helpful discussion.

\section{References}

1. Good DJ, Polverini PJ, Rastinejad F, Le Beau MM, Lemons RS, Frazier WA and Bouck NP: A tumor suppressor-dependent inhibitor of angiogenesis is immunologically and functionally indistinguishable from a fragment of thrombospondin. Proc Natl Acad Sci USA 87: 6624-6628, 1990.

2. Iruela-Arispe ML, Bornstein P and Sage H: Thrombospondin exerts an antiangiogenic effect on cord formation by endothelial cells in vitro. Proc Natl Acad Sci USA 88: 5026-5030, 1991. 
3. Weinstat-Saslow DL, Zabrenetzky VS, van Houtte K, Frazier WA Roberts DD and Steeg PS: Transfection of thrombospondin 1 complementary DNA into a human breast carcinoma cell line reduces primary tumor growth, metastatic potential, and angiogenesis. Cancer Res 54: 6504-6511, 1994.

4. Streit M, Riccardi L, Velasco P, Brown LF, Hawighorst T, Bornstein $\mathrm{P}$ and Detmar M: Thrombospondin-2: a potent endogenous inhibitor of tumor growth and angiogenesis. Proc Natl Acad Sci USA 96: 14888-14893, 1999.

5. Volpert OV, Tolsma SS, Pellerin S, Feige JJ, Chen H, Mosher DF and Bouck N: Inhibition of angiogenesis by thrombospondin-2. Biochem Biophys Res Commun 217: 326-332, 1995.

6. Kyriakides TR, Zhu YH, Yang Z and Bornstein P: The distribution of the matricellular protein thrombospondin 2 in tissues of embryonic and adult mice. J Histochem Cytochem 46: 1007-1015, 1998 .

7. Lawler J: The functions of thrombospondin-1 and -2. Curr Opin Cell Biol 12: 634-640, 2000.

8. Folkman J: Angiogenesis in cancer, vascular, rheumatoid and other disease. Nat Med 1: 27-31, 1995.

9. Tolsma SS, Volpert OV, Good DJ, Frazier WA, Polverini PJ and Bouck N: Peptides derived from two separate domains of the matrix protein thrombospondin-1 have anti-angiogenic activity. J Cell Biol 122: 497-511, 1993.

10. Adolph KW: Relative abundance of thrombospondin 2 and thrombospondin $3 \mathrm{mRNAs}$ in human tissues. Biochem Biophys Res Commun 258: 792-796, 1999.

11. Bornstein P: Diversity of function is inherent in matricellular proteins: an appraisal of thrombospondin 1. J Cell Biol 130: 503-506, 1995.

12. Streit M, Velasco P, Brown LF, Skobe M, Richard L, Riccardi L, Lawler J and Detmar M: Overexpression of thrombospondin-1 decreases angiogenesis and inhibits the growth of human cutaneous squamous cell carcinomas. Am J Pathol 155: 441-452, 1999.

13. Rofstad EK and Graff BA: Thrombospondin-1-mediated metastasis suppression by the primary tumor in human melanoma xenografts. J Invest Dermatol 117: 1042-1049, 2001.

14. Oshika Y, Masuda K, Tokunaga T, Hatanaka H, Kamiya T, Abe Y, Ozeki Y, Kijima H, Yamazaki H, Tamaoki N, Ueyama Y and Nakamura M: Thrombospondin 2 gene expression is correlated with decreased vascularity in non-small cell lung cancer. Clin Cancer Res 4: 1785-1788, 1998.

15. Tokunaga T, Nakamura M, Oshika Y, Abe Y, Ozeki Y, Fukushima Y, Hatanaka H, Sadahiro S, Kijima H, Tsuchida T, Yamazaki H, Tamaoki $\mathrm{N}$ and Ueyama $\mathrm{Y}$ : Thrombospondin 2 expression is correlated with inhibition of angiogenesis and metastasis of colon cancer. Br J Cancer 79: 354-359, 1999.

16. Kazuno M, Tokunaga T, Oshika Y, Tanaka Y, Tsugane R, Kijima H, Yamazaki H, Ueyama Y and Nakamura M: Thrombospondin-2 (TSP2) expression is inversely correlated with vascularity in glioma. Eur J Cancer 35: 502-506, 1999.

17. Fontanini G, Boldrini L, Calcinai A, Chine S, Lucchi M, Mussi A, Angeletti CA, Basolo F and Bevilacqua G: Thrombospondins I and II messenger RNA expression in lung carcinoma: relationship with p53 alterations, angiogenic growth factors, and vascular density. Clin Cancer Res 5: 155-161, 1999.
18. The World Health Organization histological typing of lung tumours. Second edition. Am J Clin Pathol 77: 123-136, 1982.

19. Abe Y, Nakamura M, Ohnishi Y, Inaba M, Ueyama Y and Tamaoki N: Multidrug resistance gene (MDR1) expression in human tumor xenografts. Int J Oncol 5: 1285-1292, 1994.

20. Abe Y, Ohnishi Y, Yoshimura M, Ota E, Ozeki Y, Oshika Y, Tokunaga T, Yamazaki H, Ueyema Y, Ogata T, Tamaoki N and Nakamura M: P-glycoprotein-mediated acquired multidrug resistance of human lung cancer cells in vivo. Br J Cancer 74: 1929-1934, 1996

21. Armstrong LC, Bjorkblom B, Hankenson KD, Siadak AW, Stiles CE and Bornstein P: Thrombospondin 2 inhibits microvascular endothelial cell proliferation by a caspase-independent mechanism. Mol Biol Cell 13: 1893-1905, 2002.

22. Guo N, Krutzsch HC, Inman JK and Roberts DD: Thrombospondin 1 and type I repeat peptides of thrombospondin 1 specifically induce apoptosis of endothelial cells. Cancer Res 57: 1735-1742, 1997

23. Tomii Y, Kamochi J, Yamazaki H, Sawa N, Tokunaga T, Ohnishi Y, Kijima H, Ueyama Y, Tamaoki N and Nakamura M: Human thrombospondin 2 inhibits proliferation of microvascular endothelial cells. Int J Oncol 20: 339-342, 2002.

24. Kamochi J, Tokunaga T, Tomii Y, Abe Y, Hatanaka H, Kijima H, Yamazaki H, Watanabe N, Matsuzaki S, Ueyama Y and Nakamura M: Overexpression of the thrombospondin 2 (TSP2) gene modulated by the matrix metalloproteinase family expression and production in human colon carcinoma cell line. Oncol Rep 10: 881-884, 2003.

25. Nakamura M, Oida Y, Abe Y, Yamazaki H, Mukai, M, Matsuyama M, Chijiwa T, Matsumoto H and Ueyama Y: Thrombospondin-2 inhibits tumor cell invasion through the modulation of MMP-9 and UPA in pancreatic cancer cells. Mol Med Rep 1: 423-427, 2008.

26. Chijiwa T, Abe Y, Ikoma N, Yamazaki H, Tsukamoto H, Suemizu H, Kawai K, Wakui M, Nishime C, Matsumoto H, Matsuyama M, Mukai M, Ueyama Y and Nakamura M: Thrombospondin 2 inhibits metastasis of human malignant melanoma through microenvironment-modification in NOD/ SCID/gamma (c) (null) (NOG) mice. Int J Oncol 34: 5-13, 2009.

27. Hawighorst T, Velasco P, Streit M, Hong YK, Kyriakides TR, Brown LF, Bornstein P and Detmar M: Thrombospondin-2 plays a protective role in multistep carcinogenesis: a novel host anti-tumor defense mechanism. EMBO J 20: 2631-2640, 2001.

28. Kyriakides TR, Zhu YH, Yang Z, Huynh G and Bornstein P: Altered extracellular matrix remodeling and angiogenesis in sponge granulomas of thrombospondin 2-null mice. Am J Pathol 159: 1255-1262, 2001.

29. Yamaguchi M, Sugio K, Ondo K, Yano T and Sugimachi K: Reduced expression of thrombospondin-1 correlates with a poor prognosis in patients with non-small cell lung cancer. Lung Cancer 36: 143-150, 2002.

30. Mascaux C, Martin B, Paesmans M, Verdebout JM, Verhest A, Vermylen P, Bosschaerts T, Ninane V and Sculier JP: Expression of thrombospondin in non-small cell lung cancer. Anticancer Res 22: 1273-1277, 2002. 